\title{
Hypotensive and bradycardic episodes in the sitting position during shoulder arthroscopy using interscalene block: can those be alerted?
}

\section{Hye Won Lee}

Department of Anesthesiology and Pain Medicine, College of Medicine, Korea University, Seoul, Korea

The sitting position of arthroscopic shoulder surgery has gained wide acceptance among orthopedic surgeons $[1,2]$. Advantages include easier airway access, placing the anatomy in the standard upright position, and less bleeding in the upright position; it also facilitates checking the effect of different positions of the arm on the involved anatomy and enables use of the weight of the arm for traction. Comparing the lateral decubitus position, favored by surgeons for three reasons: there may be no need for unnatural traction on the shoulder which may compromise capsular repairs; the procedure may be converted to open surgery without repositioning; and the incidence of traction neuropathies is significantly decreased [3-5].

Interscalene block (ISB) can be selected as primary anesthetic technique for shoulder surgery with excellent intraoperative anesthesia, muscle relaxation [6], and low complication rate [7], as well as the opportunity for postoperative analgesia [8].

Bradycardia and/or hypotension $(\mathrm{BH})$ episodes seen in 13-29\% of patients undergoing shoulder arthroscopy in the sitting position after ISB [9-12]. BH episodes, which if anticipated, are of minor significance, but which in the extreme may lead to cardiac arrest. And also serious complications such as brain and spinal cord ischemia, transient visual loss, and ophthalmoplegia caused by hypotension have been documented in patients who have undergone shoulder surgery in the upright position [13].
Seo et al [14] performed a retrospective study to investigate contributing factors for the occurrence of $\mathrm{BH}$ episodes. Anesthetic records and block data sheets of 63 patients having underwent in the sitting position during shoulder arthroscopy after ISB were reviewed and they have analyzed the demographic data, intraoperative medications, the block sides of ISB, use of epinephrine in local anesthetics, degree of sensory blockade, and percent change of heart rate or systolic blood pressure (SBP) according to $\mathrm{BH}$ episodes. $\mathrm{BH}$ episodes were defined as bradycardia and/or hypotension. Bradycardia was defined as a decline in heart rate to less than 50 bpm and a requirement of atropine. Hypotension was similarly defined as a decline in systolic blood pressure (SBP) to less than 100 $\mathrm{mmHg}$ and a requirement of ephedrine.

This current retrospective study have observed that overall percent of $\mathrm{BH}$ episodes was $20.6 \%$. The authors have founded that relatively more right side ISBs were noticed in the $\mathrm{BH}$ group than in the non- $\mathrm{BH}$ group $(P=0.048)$ and relatively higher incidence of fentanyl supplement in the $\mathrm{BH}$ group than in the non- $\mathrm{BH}$ group $(P=0.000)$. Percent change of heart rate 15 and 20 minutes after sitting positioning was significantly decreased in the $\mathrm{BH}$ group whereas percent change of SBP at 5 minutes after sitting position was significantly decreased as compared with non-BH group. They concluded that the side of ISB and fentanyl supplementation due to incomplete block can be possible new contributing factors for the occurrence

Corresponding author: Hye Won Lee, M.D., Department of Anesthesiology and Pain Medicine, College of Medicine, Korea University, 126-1, Anam-dong, Sungbuk-gu, Seoul 136-705, Korea. Tel: 82-2-920-5478, Fax: 82-2-928-2275, E-mail: hwleemd@korea.ac.kr

(c) This is an open-access article distributed under the terms of the Creative Commons Attribution Non-Commercial License (http:// creativecommons.org/licenses/by-nc/3.0/), which permits unrestricted non-commercial use, distribution, and reproduction in any medium, provided the original work is properly cited. 
of $\mathrm{BH}$ episodes in shoulder arthroscopic surgery.

Several studies hypothesized that the etiology of the hypotension and bradycardia was based on a combination of peripheral vasodilation from the sitting position, increased contractility of the heart secondary to absorbed epinephrine from block mixture, and vigorous contraction of an "empty" ventricle [15]. The most likely cause of the observed events in those having ISB for shoulder arthroscopy in the sitting position is a form of vasovagal syncope mediated by the Bezold-Jarisch reflex. The mechanism of the Bezold-Jarisch reflex is thought to be venous blood pooling (induced by the sitting position) and a heightened cardiac contractile state (induced by the P-adrenergic effects of epinephrine or isoproterenol) which result in reflex arterial vasodilation (mediated by activation of the parasympathetic nervous system) and a subsequent vagally mediated bradycardia $[16,17]$. Recently Kim's study [18] have reported that sequential compression device and elastic stockings reduce the incidence of hypotension with less hemodynamic instability in the sitting position during shoulder arthroscopy. Their study's results support that venous blood pooling induced by the upright position is associated with the hypotensive episodes.

In Seo's retrospective study, they discussed that the underlying mechanism of the newly found contributing factors such as right side of ISB and fentanyl supplement may be associated partly with sympathetic inhibition and/or parasympathetic innervation. The authors suspected that the right side of ISB involved the right side of the stellate ganglion block (SGB) which have been reported to be related with vagal reflex [19]. However, the signs induced by SGB such as Horner's sign were not described in anesthesia records and block data sheets with a limitation of this retrospective study. So a prospective and randomized study is still needed to confirm that the right side of ISB involved the right side of SGB is associated with the occurrence of $\mathrm{BH}$ episodes. It is not surprising to have observed in this study that fentanyl may be related with bradycardia or hypotension especially in the patient of stressful condition such as incomplete blocks which were suspected in this current study. The studies have discussed that role of endogenous opioids is related with vasovagal syncope [20] and fentanyl inhibits GABAergic transmission to cardiac vagal neurons in the nucleus ambiguus, providing one mechanism for the opioid induced bradycardia [21].

The interesting observation of this current retrospective study is to alert anesthesiologists to the possibility of potentially dangerous BH events when using right side of ISB or fentanyl supplement for shoulder arthroscopy in the sitting position; when significant decrease of heart rate at 15 and 20 minutes after sitting positioning or significant decrease of $\mathrm{SBP}$ at 5 minutes after sitting position are observed. Therefore progression from prodromal symptoms to cardiovascular collapse or other serious complications may be avoided if therapeutic intervention is applied as early possible and as appropriately.

\section{References}

1. Skyhar MJ, Altcheck DW, Warren RF, Wickiewicz TL, O'Brien SJ. Shoulder arthroscopy with the patient in the beachchair position. Arthroscopy 1988; 4: 256-9.

2. D'Alessio JG, Rosenblum M, Shea KP, Freitas DG. A retrospective comparison of interscalene block and general anesthesia for ambulatory surgery shoulder arthroscopy. Reg Anesth 1995; 20: 62-8.

3. Ellman H. Arthroscopic subacromial decompression: analysis of one to three year results. Arthroscopy 1987; 3: 173-81.

4. Klein AH, France JC, Mutschler TA, Fu FH. Measurement of brachial plexus strain in arthroscopy of the shoulder. Arthroscopy 1987; 3: 45-52.

5. Peruto CM, Ciccotti MG, Cohen SB. Shoulder arthroscopy positioning: lateral decubitus versus beach chair. Arthroscopy 2009; 25: 891-6.

6. Brown AR, Weiss R, Greenberg C, Flatow EL, Bigliani LU. Interscalene block for shoulder arthroscopy: comparison with general anesthesia. Arthroscopy 1993; 9: 295-300.

7. Bishop JY, Sprague M, Gelber J, Krol M, Rosenblatt MA, Gladstone J, et al. Interscalene regional anesthesia for shoulder surgery. J Bone Joint Surg Am 2005; 87: 974-9.

8. Singelyn FJ, Lhotel L, Fabre B. Pain relief after arthroscopic shoulder surgery: a comparison of intraarticular analgesia, suprascapular nerve block, and interscalene brachial plexus block. Anesth Analg 2004; 99: 589-92.

9. Kahn RL, Hargett MJ. $\beta$-adrenergic blockers and vasovagal episodes during shoulder surgery in the sitting position under interscalene block. Anesth Analg 1999; 88: 378-81.

10. D'Alessio JG, Weller RS, Rosenblum M. Activation of the Bezold-Jarisch reflex in the sitting position for shoulder arthroscopy using interscalene block. Anesth Analg 1995; 80: 1158-62.

11. Liguori GA, Kahn RL, Gordon J, Gordon MA, Urban MK. The Use of metoprolol and glycopyrrolate to prevent hypotensive/bradycardic events during shoulder arthroscopy in the sitting position under interscalene block. Anesth Analg 1998; 87: 1320-5.

12. Sia S, Sarro F, Lepri A, Bartoli M. The effect of exogenous epinephrine on the incidence of hypotensive/bradycardic events during shoulder surgery in the sitting position during interscalene block. Anesth Analg 2003; 97: 583-8.

13. Pohl A, Cullen DJ. Cerebral ischemia during shoulder surgery in the upright position: a case series. J Clin Anesth 2005; 17: 463-9. 
14. Seo KC, Park JS, Roh WS. Factors contributing to episodes of bradycardia hypotension during shoulder arthroscopic surgery in the sitting position after interscalene block. Korean J Anesthesiol 2010; 58: 38-44.

15. Campagna JA, Carter C. Clinical relevance of the BezoldJarisch reflex. Anesthesiology 2003; 98: 1250-60.

16. Kinsella SM, Tuckey JP. Perioperative bradycardia and asystole: relationship to vasovagal syncope and the Bezold-Jarisch reflex. Br J Anaesth 2001; 86: 859-68.

17. Donald DE, Shepard JT. Reflexes from the heart and lungs: physiological curiosities or important regulatory mechanisms. Cardiovasc Res 1978; 12: 446-69.

18. Kim JY, Lee JS, Lee KC, Kim HS, Park CH, Kwak HJ. The effect of sequential compression device on hypotension in the sitting position during shoulder arthroscopy; a comparison with elastic stocking. Korean J Anesthesiol 2009; 57: 417-21

19. Fujii K, Yamaguchi S, Egawa S, Hamaguchi S, Kitajima T, Minami J. Effects of head-up tilt after stellate ganglion block on QT Interval and QT Dispersion. Reg Anesth Pain Med 2004; 29: 317-22.

20. Wallbridge DR, Maclntyre HE, Gray CE, Oldroyd KG, Rae AP, Cobbe SM. Role of endogenous opioids and catecholamines in vasovagal syncope. Eur Heart J 1996; 17: $1729-36$

21. Griffioen KJ, Venkatesan P, Huang ZG, Wang X, Bouairi $E$, Evans $C$, et al. Fentanyl inhibits GABAergic neurotransmission to cardiac vagal neurons in the nucleus ambiguous. Brain Res 2004; 1007: 109-15. 